\title{
Testing for constituents: A response from Functional Discourse Grammar
}

\author{
J. Lachlan Mackenzie ${ }^{\mathrm{a}}$ \\ a VU Amsterdam, lachlan mackenzie@hotmail.com.
}

Paper received: 20 October 2018

Published online: 20 January 2019

\begin{abstract}
Timothy Osborne has surveyed a very large number of published introductions to grammatical analysis, all of which share the assumption that syntactic argumentation is to be conducted without reference to the meanings, uses and contexts of the example sentences. The purpose of Osborne's article is to examine how well syntactic tests identify subphrasal strings as constituents. The aim of this discussion note is not to engage directly with this issue but to consider, from the viewpoint of Functional Discourse Grammar (FDG), the validity of the autonomous syntax assumption shared by Osborne and the authors whose work he considers. The note dwells on the hidden presence of functional and interactive notions in a methodology based on syntactic 'tests' and it is suggested that the difficulties encountered by that methodology (notably with regard to coordination) can be resolved insightfully by FDG with its four levels of analysis.
\end{abstract}

Keywords: coordination, discourse acts, Functional Discourse Grammar, pseudo-clefting, pseudogapping, subacts, syntactic argumentation, topicalization

This discussion note is an invited response to Osborne (2018) from the viewpoint of functional linguistics and more specifically that of Functional Discourse Grammar (FDG) as developed in the first two decades of this century (Hengeveld and Mackenzie 2008). FDG shares with the focus article the ambition of distinguishing grammatical from ungrammatical forms but its methodological presuppositions are very different from those presented by Osborne. As a consequence, the debate central to his argument, that between constituency and dependency, will play a smaller part in the following than a consideration of an assumption shared by both sides of the debate, namely that syntactic argumentation is to be conducted without reference to the meanings, uses and contexts of the example sentences. It will be suggested in brief format that a functional grammar can provide deeper insight into the phenomena that Osborne has

Language Under Discussion, Vol. 5, Issue 1 (April 2018), pp. 45-51

Published by the Language Under Discussion Society

This work is licensed under a Creative Commons Attribution 4.0 License. 
presented in the wake of his extremely thorough exploration of "several dozen linguistics, syntax and grammar books" (p. 9).

FDG takes as its point of departure the observation that human verbal interaction divides into Discourse Acts, each of which makes its own contribution to the ongoing communicative exchange, and seeks to offer understanding of how Linguistic Expressions encode Discourse Acts. To achieve this aim, FDG provides two analyses of how the Speaker's communicative intention is formulated, known as the Interpersonal and Representational Levels of analysis, as well as two analyses of how the formulation is encoded, known as the Morphosyntactic and Phonological Levels. All but the most formulaic of Discourse Acts involve all four levels of analysis, and none of the levels has priority over the others. Each of the four levels is modular in the sense of being domain-specific: the Interpersonal Level, for example, covers all and only all the rhetorical and pragmatic aspects of the Discourse Act, while the Representational Level accounts exclusively for its semantic aspects. The Morphosyntactic Level is solely concerned with morphological and syntactic properties and, together with the Phonological Level, serves to specify the linguistic forms that reflect the distinctions made at the formulation levels. The observation that justifies all functional approaches to grammar is that there is a large degree of homology between formulation and encoding, operationalized in FDG as the principles of iconicity, domain integrity and functional stability.

Given these theoretical presuppositions, FDG cannot share an assumption made by both the dependency grammars defended by Osborne and the constituency grammars he argues to be inferior, namely that syntactic structure can and indeed should be analysed independently of the uses to which it is put in verbal interaction, i.e. without also contemplating the rhetoricalpragmatic, semantic and phonological properties of the items under consideration. The objectification of the data items this entails is apparent in the prominence given by the focus article (and the books cited therein) to the application of "tests", which involve manipulations of those items much in the manner of mathematical operations such as addition, subtraction, multiplication, division and exponentiation. These tests yield results which are evaluated for their grammaticality in order to reveal the presence (or absence) of syntactic constituents, the ultimate purpose being to provide evidence for the relative advantages and drawbacks of constituency and dependency diagramming.

However, the very names of many of the tests expose the hidden presence of interpersonal and representational notions that, from a functionalist viewpoint, are capable of explaining the phenomena presented. Consider Osborne's discussion of (1) (also his example (1)), for which he provides rivalling constituent and dependency trees on p. 2:

(1) Trees can show syntactic structure.

On p. 3 we find mention of the three tests: Topicalization, Pseudoclefting and Answer Fragment, which all have noticeably functional-sounding names that in the last analysis invoke the use of language in interaction. In FDG, Topic is a pragmatic function ${ }^{1}$ that can be assigned to one or more Subact, a Subact being a minimal unit of the activity performed by the utterance of a Discourse Act. A speaker uses a Subact either to refer (in a Referential Subact) or to predicate (in an Ascriptive Subact). In (2) (= Osborne's (2a)), the words syntactic structure correspond to

\footnotetext{
${ }^{1}$ FDG recognizes three pragmatic functions: Topic, Focus and Contrast.
} 
a Topic-marked Referential Subact, and in (3) (= Osborne's (3a)), the words show syntactic structure correspond to two Topics, a Topic-marked Ascriptive Subact (show) and a Topicmarked Referential Subact (syntactic structure):

(2) ... and syntactic structure, trees can show.

(3) ... and show syntactic structure, trees can.

When it comes to testing the constituency of trees, however, Osborne (2018: 3) states that topicalization is "[i]napplicable". This remark betrays a view of topicalization as necessarily involving a movement rule displacing a Topic from some other position in the syntactic structure. But from a discourse-grammatical viewpoint that eschews movement rules, (4)-as indeed does (1)-involves a Topic-marked Subact (trees) just as much as (2) and (3), and its clause-initial position can be explained in exactly the same way as the items in bold print in those examples:

(4) $\quad \ldots$ and trees can show syntactic structure.

Finally, the ungrammaticality of (5) (= Osborne's (5a)) is a direct consequence of syntactic being only part of the Subact expressed as syntactic structure, for which reason it cannot function as a Topic:

(5) *... and syntactic, trees can show structure.

Topic is thus the common explanatory function behind the grammaticality of (2)-(4) and the ungrammaticality of (5).

Pseudoclefting and Answer Fragment are presented by Osborne as two separate phenomena but from an FDG standpoint they are very much the same, chiefly differing in involving one or two interactants respectively: in (6a) (= his (2b)), the speaker is, as it were, answering her own question while in $(6 \mathrm{~b})(=$ his $(2 \mathrm{c}))$, a hearer answers the question:

(6) a. What trees can show is syntactic structure.

b. What can trees show? - Syntactic structure.

Both items in bold print correspond to Subacts marked for the pragmatic function Focus at the Interpersonal Level. The hearer's response in (6b) is a Discourse Act with a single Subact-such single Subacts are always Focus by default. In FDG, pseudoclefting does not result from the manipulation of a single clause, as is proposed both by Osborne and by those whom he criticizes: it not only involves Focus-assignment at the Interpersonal Level but also is specifically distinct at the Representational Level in being an equative clause (as is manifest in its copular structure). All in all, then, the properties of the data presented here are comprehensible provided that the items are seen as reflections of the underlying pragmatic and semantic representations. The autonomy of syntax presupposed by both sides of the debate staged in the focus article is undermined by the indirect allusions to discourse structure (implicit in the three dots in Osborne's examples (6a), (7a), (8a) and (9a)) and to verbal interaction (the question-answer sequences in his examples $(6 \mathrm{c}),(7 \mathrm{c}),(8 \mathrm{c})$ and $(9 \mathrm{c}))$, by the use of impure manipulations (as is 
actually conceded by Osborne in footnote 2 on p. 3 of his article) and, as already mentioned, by his use of names for the tests that allude to the functionality of the structures without any exploration of that functionality.

A further pitfall of the test methodology (which is in evidence on Osborne's p. $16 \mathrm{ff}$.) is that the ungrammaticality of certain structures is envisaged from the viewpoint of the test, while in many cases it is explicable for independent reasons. Consider (7), corresponding to his example (20), and the examples in (8), all of which arise from application of one test or another:

(7) Drunks would put off the customers.

(8) a. *Drunks would do it the customers. (Osborne's (22b))

b. *Do what the drunks the customers? (Osborne's (22j))

c. *Drunks would put off the them. (Osborne's (23b))

d. *It was customers that drunks would put off the. (Osborne's (23i))

(8a) is out since do here is followed by two NP objects, while its template requires one NP only, a fact which in turn follows from its semantic properties. (8b) similarly cannot be parsed: English cannot question a verb, a possibility found in other languages and investigated by Idiatov and Van der Auwera (2004). (8c) is ruled out by the inherent definiteness of personal pronouns, and (8d)-in FDG terms-by the impossibility of applying the pragmatic function Contrast (which triggers the cleft construction) to only part of the Subact in question. On occasions, even the sentences that prompt the test seem ungrammatical, as with the question in (9):

(9) What would drunks do concerning the customers? - *Put off. (Osborne’s (22d))

The point that is most salient in the data exemplified in (7) and (8), however, is that put off (in the sense of 'disconcert') is, for semantic reasons, highly transitive; i.e., in FDG terms, it is strongly associated with an Actor-Undergoer frame. The ungrammaticality of Put off in (9) and indeed the impeccability of Put them off as an answer are entirely understandable on this, semantic, basis. This leads us to the question of the omission of put off in (10), judged by Osborne to be ungrammatical:

(10) *Drunks would the customers. (Osborne's (22h))

In a discourse context of the type shown in (11), however, (9) is generally taken to be grammatical:

(11) Flower-sellers put off the staff, and drunks would the customers.

This constitutes an example of 'pseudogapping' (a term introduced by Levin 1980; cf. her structurally parallel example I picked up a newspaper, and Lynn might/will/did a magazine, 1980: 75). ${ }^{2}$ The omissibility of put off as a unit is entirely unsurprising given its semantic

\footnotetext{
${ }^{2}$ I am aware that, as Hoeksema (2006: 335) has phrased it, “[j]udgments on pseudogapping sentences are often insecure, because this type of ellipsis itself is often viewed as marginal ... and informal, and in addition to this,
} 
coherence, and indeed it is treated as a single lexeme in FDG. Osborne himself elsewhere provides convincing coordination evidence for the coherence of put off and for its analogous status to a single transitive verb like offend, cf. his (22a) and (24a).

A conclusion drawn from Osborne's Section 4 is that coordination "actually seems to consistently support phrase structure" (2018: 18). However, he is fully aware-and his Section 7.1 is devoted to this issue-that coordination tests can yield results that for syntacticians are counter-intuitive, as in, for example, (12):

(12) Bill gave [you these] and [me those] today. (Osborne's (27i))

Here you these and me those are seen, for reasons that have to do with syntax, as not being constituents. Semantically, too, they do not form units and in FDG they would accordingly not be units at the Representational Level. However, in FDG it is at the Interpersonal Level that coordination of units of Discourse Acts is accounted for, as involving the multiple occurrence of either Topic-marked or Focus-marked Subacts (but never a mixture). In (12), Bill is a Topic, while gave and today may or may not be in Focus (that depends on the preceding context and the information shared between Speaker and Addressee); in any case, you and these, and me and those are all Focus, and it is this, not their putative status as constituents of a syntactic structure, which enables the grammaticality of (12). Similarly, the option of multiple Topics and/or multiple Foci also explains all the data in Osborne's (27).

The project of banning all references to meaning, use and phonology is, FDG would argue, not one that can be sustained. This is apparent from time to time in Osborne's argument. On p. 17 , for instance, he attributes the ungrammaticality of (13) (his (24a)) to the idiosyncrasy of put off and piss off:

(13) *Drunks would put and piss off the customers.

Osborne is surprised that coordination does not work here (as a syntactician might expect), and he is surely right to appeal to the fact, alluded to above, that put off and piss off are each meaning units (with the senses 'disconcert' and 'annoy' respectively); but this weakens the assumption of autonomous syntax. More generally, his identification of "an understanding of constituents from intuition" (p. 20) appears to involve recourse to units of meaning, as where he quotes Poole (2002: 29) as writing, "We all share the feeling that, for example, at the station ... forms some kind of unit". Given the inaccessibility of syntactic structure to introspection (for most of us at least), that universal feeling must be based on an identification of at the station as a meaning unit, specifically as pinpointing a location (as proposed in FDG). Similar observations apply to syntacticians' disregard of units of interaction, specifically the Subacts (i.e. the minimal units of communicative activity) that make up the Communicated Content of Discourse Acts. Osborne's Table 5 (pp. 21-22) presents six tests for 'constituent status' drawn from the literature, but all of these are rooted, from an FDG perspective, in the use (or non-use) of Subacts, see Table 1.

shows a great deal of variation among speakers of English". Nevertheless, I am confident that pseudogapping is found with sufficient frequency in usage to be considered part of English grammar, as is confirmed by Miller's (2014) corpus study of the construction. 
Table 1. FDG interpretation of six syntactic tests

\begin{tabular}{|l|l|}
\hline Test & FDG analysis at the Interpersonal Level \\
\hline Omission & $\begin{array}{l}\text { Non-performance of a Subact (i.e. the speaker refrains from carrying out a } \\
\text { potential minimal unit of communicative activity) }\end{array}$ \\
\hline Topicalization & $\begin{array}{l}\text { Assignment of Topic function to a Subact (i.e. the speaker treats the } \\
\text { information conveyed in a minimal unit of communicative activity as topical) }\end{array}$ \\
\hline Answer fragments & $\begin{array}{l}\text { Discourse Acts consisting of a single Subact with the Focus function (i.e. the } \\
\text { speaker performs a Discourse Act that contains only one minimal unit of } \\
\text { communicative activity, which is necessarily in focus) }\end{array}$ \\
\hline VP-ellipsis & $\begin{array}{l}\text { Non-performance of Subacts that would re-express the Focus Subacts of the } \\
\text { preceding Discourse Act (i.e. to avoid reduplication, the speaker refrains from } \\
\text { carrying out one or more minimal units of communicative activity that have } \\
\text { already been in focus) }\end{array}$ \\
\hline Passivization & $\begin{array}{l}\text { Neutralization of semantic functions across the Representational and } \\
\text { Morphosyntactic Levels, often associated with assignment of Topic to the } \\
\text { Subject (i.e. the speaker assigns the same morphological marking to an } \\
\text { Undergoer as she would assign to a (typically topical) Actor) }\end{array}$ \\
\hline Proform substitution & $\begin{array}{l}\text { Performance of a Subact associated with more schematic semantic } \\
\text { information (i.e. the speaker gives reduced information, confident that the } \\
\text { hearer can reconstruct the full information) }\end{array}$ \\
\hline
\end{tabular}

Finally, there is a tacit admission on p. 25 that the Phonological Level also cannot be dispensed with, where Osborne writes of certain examples in his (27) that "they improve ... if read with rising-falling prosody". What is implicit here are the prosodic consequences of assigning the pragmatic function Contrast to the respective Subacts at the Interpersonal Level of FDG.

For various of the reasons adumbrated here, FDG would take issue with the very first sentence of the focus article, which states that syntax is "of course" central to "all theories of language". Just like Simpler Syntax, FDG rejects "syntactocentrism" (Culicover and Jackendoff 2005: 21) and takes the position that morphosyntax has its role to play, but always in conjunction with textuality, pragmatics, semantics and phonology. In fact, it is sympathetic to the view developed by Schoenemann (1999) that whatever complexity there may be in syntax, "the actual grammatical rules in any specific language are simply cultural inventions created to allow speakers to describe the salient features of their semantic universe" (1999: 311), i.e. the syntax has an ancillary role with respect to the conveyance of meaning. Schoenemann (1999: 330) argues from an evolutionary perspective that the hierarchical nature of syntactic structurewhich, as Osborne (p. 6) stresses, is common to both constituency and dependency approachesis fully to be expected since "the evolution of hierarchical systems becomes increasingly probable as the level of complexity of the resultant systems increases". Furthermore, he holds "that new semantic conceptualizations of the world must necessarily have evolved prior to the evolution of the syntactical devices which allow us to codify these semantic concepts since there would otherwise be no selective reason for any given syntactical structure to exist" 
(Schoenemann 1999: 330, his emphasis), a point he then demonstrates for a rather complete list of presumed universal properties of syntactic structure.

This brief discussion note has not touched on the central question addressed by the focus article, whether the results of syntactic tests align better with dependency syntax, as the author contends, or with phrase structure syntax. Instead, from the perspective of Functional Discourse Grammar (FDG), we have questioned the assumption of autonomous syntax and the methodology that is associated with it, involving manipulations of strings of symbolic elements (words and phrases) without regard to their meaning, use and prosodic properties. It has been suggested that FDG is better placed to offer explanatory accounts of the grammaticality and ungrammaticality of the examples presented.

\section{References}

Culicover, Peter W. and Ray Jackendoff. 2005. Simpler Syntax. Oxford: Oxford University Press.

Hengeveld, Kees and J. Lachlan Mackenzie. 2008. Functional Discourse Grammar: A Typologically-based Theory of Language Structure. Oxford: Oxford University Press.

Hoeksema, Jack. 2006. Pseudogapping: Its syntactic analysis and cumulative effects on its acceptability. Research on Language and Computation 4: 335-352. DOI: 10.1007/s11168-006-9023-x.

Idiatov, Dmitry and Johan van der Auwera. 2004. On interrogative pro-verbs. In Ileana Comorovski and Manfred Krifka (eds.), Proceedings of the Workshop on the Syntax, Semantics and Pragmatics of Questions, ESSLLI 16, August 9-13, 2004, Nancy, France, 17-23. Nancy: The European Association for Logic, Language and Information.

Levin, Nancy Sue. 1980. Main-verb ellipsis in spoken English. OSU WPL 24: 65-165.

Miller, Philip. 2014. A corpus study of pseudogapping and its theoretical consequences. In Christopher Piñon (ed.), Empirical Issues in Syntax and Semantics 10: 73-90. Available at http://www.cssp.cnrs. fr/eiss10/eiss10_miller.pdf.

Osborne, Timothy. 2018. Tests for constituents: What they really reveal about the nature of syntactic structure. Language under Discussion 5.1: 1-41.

Poole, Geoffrey. 2002. Syntactic Theory. New York: Palgrave.

Schoenemann, P. Thomas. 1999. Syntax as an emergent characteristic of the evolution of semantic complexity. Minds and Machines 9: 309-346. 